\title{
Comparison of memory impairments among two groups of patients with diabetes with different disease durations
}

\author{
Mohamad Ali Heidari Gorji ${ }^{1}$, Heshmatollah Ghahremanlu², Mohsen Haghshenas ${ }^{3+}$, Mohammad Reza Sadeghi ${ }^{4 *}$ and \\ Ali Morad Heidari Gorji
}

\begin{abstract}
Background: Modest cognitive impairment has been reported in adults with diabetes. Therefore, we aimed to compare memory impairments among two groups of patients with diabetes with different disease durations. This study included 120 patients treated at the diabetes clinic at Imam Khomeini Hospital, Ardebil, Iran, over 14 months (2009-2010). The patients were divided into two groups according to their disease duration as $>5$ years or $<1$ year (recently diagnosed). The two groups were approximately matched in terms of age and education. Memory impairments were examined using the Wechsler Memory Scale. Data are presented descriptively, and were compared between groups using multivariate analysis of variance.
\end{abstract}

Finding: Overall, there were no significant differences in total scores or individual subscales between the two groups. However, 59\% of all patients had below-average scores on the Wechsler memory questionnaire.

Conclusion: Both groups reported below-average scores on the Wechsler Memory Scale that were independent of disease duration. The present study agreed with the results of other studies showing impaired memory among patients with diabetes. The current findings require further investigation in longitudinal studies.

\section{Background}

Insulin is a key cellular signaling molecule. Patients with diabetes are unable to produce or efficiently utilize insulin, resulting in hyperglycemia [1]. Some studies have explored the relationship between insulin and cognitive disease among patients with diabetes [2,3]. It seems that hyperglycemia may affect cognition and lead to memory defects in daily life in patients with diabetic [4]. Experimental studies have also revealed that insulin can influences memory function in animals [5-7]. The hippocampus is established as the main site of memory formation and learning, and studies have determined the levels of insulin in the hippocampus. Diabetes may result in decreased insulin levels in the hippocampus because of impaired insulin transportation to the hippocampus [8], and may therefore affect memory. The overall changes in glucose levels are related

\footnotetext{
* Correspondence: Dr_sadegh54@yahoo.com

${ }^{\dagger}$ Equal contributors

${ }^{4}$ Department of Psychology, Mazandaran University of Medical Sciences, Sari, Iran

Full list of author information is available at the end of the article
}

to memory functions [9-11]. Although some studies found no difference between a control and a diabetic group in terms of cognitive function [12], earlier studies have yielded inconsistent results. Furthermore, some chronic diseases, independent of the type of disease, may affect cognitive function. However, in previous studies, the effect disease duration was either overlooked or the findings were contradictory $[12,13]$. Therefore, in this study, we divided patients with diabetes into two groups according to disease duration to examine the impact of disease duration on memory impairment.

\section{Methods \\ Patients}

The present study was a cross-sectional comparative study of patients with diabetes treated over 14 months (20092010) at the diabetes clinic of Imam Khomeini Hospital, Ardebil, Iran. This study approved by the research committee at Ardebil Azad Islamic University. The patients were selected by an objective-oriented method based on their disease duration. Based on literature patients with

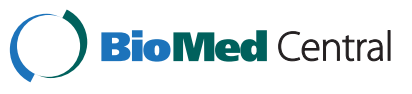


diabetes type 2 considered as a sample. Patients were screened based on the following inclusion criteria: presence of type 2 diabetes, aged 18-60 years, and undergoing usual medical treatment at our diabetes clinic. Patients with co-morbidities, other chronic disease or psychiatric problems were excluded. Overall, 120 patients consented to participate in the study ( 86 females and 34 males). Of these, 60 patients had diabetes for $>5$ years and 60 were newly diagnosed, with diabetes duration of $<1$ year. The two groups were closely matched in terms of age and education.

\section{Outcomes}

Demographic characteristics were evaluated by questionnaire, which covered age, sex, disease duration, education and regular medications. Memory was evaluated by the Wechsler Memory Scale (WMS), a well-established, validated questionnaire. We used the WMS translated by Nasri\& Bageri using the WMS, each type of memory is evaluated using two stimuli (auditory and visual) and two types of tasks (recall and recognition). The questionnaire was applied with a 30-minute interval between stages. We also included the Digits test. Eight subtests were estimated Information \& Orientation; Spatial Span; Mental Control; Visual Memory; Digit Span; Letter Number; and Word Association. The final memory score was determined as the total of all subscales [10]. Total score of 100 is considered the cutoff value in validity tests for 'normal' memory function [14].

\section{Analysis}

SPSS software version 14 (SPSS Inc., Chicago, IL) was used for all analyses. Frequencies and multivariate analysis of variance were used to determine the percentages of below- and above-average scores, and to compare the two groups for each memory questionnaire subscale.

\section{Findings}

We hypothesized that there would be significant differences between the two groups in terms of memory function derived from the WMS subscales. However, as shown in Table 1, there were no significant

Table 1 Demonstrate multi variable variance analysis in two different groups on memory subscales

\begin{tabular}{lllllll}
\hline Sources & Variables & S & Df & MS & $\mathbf{F}$ & $\mathbf{P}$ \\
\hline Groups & linformation \& Orientation & $1 / 200$ & 1 & $1 / 200$ & $088 / 0$ & $0767 / 0$ \\
& Spatial Span & $833 / 0$ & 1 & $0833 / 0$ & $0124 / 0$ & $0725 / 0$ \\
& Mental Control & $008 / 0$ & 1 & $008 / 0$ & $006 / 0$ & $0938 / 0$ \\
& Visualize memory & $208 / 0$ & 1 & $208 / 0$ & $022 / 0$ & $0844 / 0$ \\
& Word association & $1 / 008$ & 1 & $1 / 008$ & $0520 / 0$ & $0509 / 0$ \\
& Digit Span & $133 / 0$ & 1 & $0133 / 0$ & $0225 / 0$ & $0603 / 0$ \\
& Letter number & $8 / 533$ & 1 & $8 / 533$ & $0 / 096$ & $045 / 0$ \\
\hline
\end{tabular}

differences in any subscale or total score between the two groups $(P>0.005)$. Therefore, the null hypothesis was accepted.

There was $45 \%$ smoking and no drug abusing in our sample. Among 120 selected subjects 34 cases were male and 86 were female. Mean age was $41 / 46 \ldots+10.16 \%$ and age range were between $30-45.11 \%$ of patients were working and $14.2 \%$ were retired and $46.7 \%$ of patients was home maker and rest non- working. All participants were literate among them $40.8 \%$ had elementary education level and rest higher. Among participants 52\% of memory scores lower than normal and $27 \%$ were medico rite, only $19 \%$ of patient were higher than appropriate.

\section{Discussion}

The present study was conducted to compare the memory function of two groups of patients with diabetes according to disease duration. We found a marked relationship between diabetes and memory, as just over half of the patients $(52 \%)$ had below-average scores on the WMS. These results were consistent with those reported by Rogers [15] and Sani et al [16], who described that diabetes and altered insulin signaling may affect memory function. In another study [8], glucose fluctuations were shown to disrupt memory formation in rats. However, the results are not consistent with those reported by Amine et al. [17]. However, this difference may be due to the inclusion of adolescents with type 1 diabetes in the study by Amine et al. [17]. Nevertheless, insulin and glucose are necessary to maintain normal brain function; thus, the disruption of insulin action is likely to cause weaknesses in daily memory function. Our current results showed no difference in memory between two groups according to duration of diabetes. However, in a study by Grodstein et al [18], increases in disease duration were found to decrease memory function, although their findings may reflect the age of participants, as that study included older adults. It is already well established that memory is greatly affected by age. Thus, we should interpret our findings in relation to other related studies, particularly those Sani et al [16] and Agostina et al [19], who found that diabetes in any stage of life may negatively affect memory function. In fact, studies have clearly demonstrated that decreases in insulin levels may substantially impair memory function, independent of disease duration [20-22].

\section{Conclusion}

The results of our study and earlier studies $[2,4,9,10]$ have demonstrated a strong relationship between memory problems and diabetes. Thus, patients must be aware and attempt to control their diabetes by following their physician's advice to prevent diabetes-associated memory impairments. 


\section{Competing interest}

The authors declare that they have no competing interests.

\section{Authors' contributions}

Each author has participated actively and sufficiently in this study. MHG and MRS conceived the idea and design of the study, interpretation of data, and data collection and drafted the manuscript. $\mathrm{HG}$ and $\mathrm{MH}$ conceived the idea and supervised all work processes and gave advices and revise. $\mathrm{MH}$ and $\mathrm{AHG}$ made substantial contribution to writing, editing and review of literature. Each author revised critically the manuscript and provided final approval of the version to be published and believes that the manuscript represents honest work.

\section{Acknowledgements}

We would like to thank the chairperson of psychology department of Ardebil Azad University, Iran, for his scientific helps and advices.

\section{Author details}

${ }^{1}$ Department of Nursing, Mazandaran Medical Science University, Sari, Iran. ${ }^{2}$ Department of Psychology, Mashhad, Iran. ${ }^{3}$ Department of Pediatric, Babol Medical Science University, Babol, Iran. ${ }^{4}$ Department of Psychology, Mazandaran University of Medical Sciences, Sari, Iran.

Received: 11 December 2011 Accepted: 2 May 2012 Published: 16 July 2012

\section{References}

1. Soleiman Panah SA: Introduce to diabetes and blood glucose control methods. Ardebil: Sharvan press; 1996:10-11.

2. Augustins MA, Geert JB, Edward HF, Kappelle J, Roy PC: The effects of type 1 diabetes on cognitive performance. Diabetes Care 2005, 28(3):1800-1807.

3. Sridhar GR: Psychiatric co-morbidity \& diabetes. Indian J Med Res 2007, 125:311-320.

4. Sommerfield AJ, Deary IJ, Vincent MA, Frier BM: Short-term, delayed, and working memory are impaired during hypoglycemia in individuals with type 1 diabetes. Diabetes Care 2003, 26:390-396.

5. Das P, Scaborough WT, Movrton D: Electrophisiological and behavioral phenotype of insulin receptor defective mice. J Psychol Behavior 2005, 82:287-296.

6. Vaffayi AA, Rashidi pur: Glucocorticoid receptors have different effects on consolidation and memories of memory space on Morris maze model: First national conference of metabolism and glands in Isfahan, Abstract book; 2007.

7. Shafiyi MR, Allayi HA, Rayeisi P: Study effects of insulin on rat brain electric function. First national conference of metabolism and glands in Isfahan, Abstract book; 2007.

8. Ewan C, Williamson A, Crimmon RJ, Sherwin RS: Cognitive and neural hippocampal effects of long-term moderate recurrent hypoglycemia. Diab 2006, 55:1080-1095.

9. Randall J, Carol E, Winocur G, Wolever T: Cognitive performance is associated with glucose regulation in healthy elderly persons and can be enhanced with glucose and dietary carbohydrates. Am J Clin Nutr 2001, I72(3):825-836.

10. Cosway R, Strachan MWJ, Dougall A, Frier BM, Deary IJ: Cognitive function and information processing in Type 2 diabetes. Diabet Med 2001, 18:803-810.

11. Arvanitakis Z, Wilson R, Li Y, Aggarwal NT, David AB: Diabetes and function in different cognitive systems in older individuals without dementia. Diabetes Care 2006, 29:560-565.

12. Gareth S: An Assessment of Cognitive Impairment in Young Adults with Type 1 Diabetes Mellitus. Project for School of Psychology; 2008. available in dbspin. com/content/academic/Thesis.pdf.

13. Prescott JH, Richardson JTE, Christopher, Gillespie R: Cognitive function in diabetes mellitus: the effects of duration of illness and glycaemic control. Br J Clin Psychol 2011, 29(2):167-175.

14. Oranghi M: Standardization of Wechsler memory scale on Shiraz. Psychiatry Institute: Master Dissertation in clinical psychology; 2000.

15. Rarger MA, Watson GS, frey WH, Baker LD, cholerton B, keeling ML: Effects of intranasal insulin on cognitive in memory impaired older adults: modulation by APOE genotype. Neurobiol Aging 2006, 27:451-458.

16. Manschot SM, Brands AMA, van der Grond J, Kessels RPC: Brain magnetic imaging correlates of impaired cognition in patients with type 2 diabetes. Diabetes 2006, 55:1106-1113.
17. Amine M, Sartippur M, Haghigi S, Attari A: Comparison of learning in children and adolescences with diabetes type one by control group: First national conference of metabolism and glands in Isfahan. Abstract book. 2007.

18. Grodstein F, Chen J, Wilson RS, Manson JE: Type 2 Diabetes and Cognitive Function in Community-Dwelling Elderly Women. Diabetes Care 2001, 24:1060-1065. by the American Diabetes Association. Inc.

19. Brands AMA, Kessels RPC, Henselmans J, Johanna W, van der Beek boter, Jaap Kappelle L, et al: Cognitive performance, psychological well-being, and brain magnetic resonance imaging in older patients with type 1 diabetes. Diabetes 2006, 55:1800-1806.

20. Auer RN, Wieloch T, Olsson Y, Siesjo BK: The distribution of hypoglycemic brain damage. Acta Neuropathol 1984, 64:177-191.

21. Cosettechoeiri L, Kimberley H, Durkin J, Simard CJ, Renaud J-M, Claud M: Longitudinal evaluation of memory performance and peripheral neuropathy in the Ins Akita mice. Behavioral Brain Research 2005, 157:31-38.

22. Carol E, Randall J, Hebblethwaite S, Jenkins DJA: Memory impairments associated with postprandial hyperglycemia and glycemic control. Diabetes Care 2004, 27:634-635. by the American Diabetes Association.

doi:10.1186/1756-0500-5-353

Cite this article as: Heidari Gorji et al:: Comparison of memory impairments among two groups of patients with diabetes with different disease durations. BMC Research Notes 2012 5:353.

\section{Submit your next manuscript to BioMed Central and take full advantage of:}

- Convenient online submission

- Thorough peer review

- No space constraints or color figure charges

- Immediate publication on acceptance

- Inclusion in PubMed, CAS, Scopus and Google Scholar

- Research which is freely available for redistribution

Submit your manuscript at www.biomedcentral.com/submit
C BioMed Central 